\title{
Lipoatrophy associated with daily growth hormone injections
}

\author{
Priya Darshani Chhiba $\mathbb{D}$ and David Segal \\ University of the Witwatersrand, Wits Donald Gordon Medical Centre, Johannesburg, South Africa
}

Correspondence should be addressed to $D$ Segal

Email

david@endo.co.za

\section{Summary}

Recombinant human growth hormone therapy ( $\mathrm{rhGH}$ ) has been available since 1985 for a variety of conditions and has expanded the indications for rhGH therapy and the number of patients receiving therapy. The very nature of the therapy exposes individuals to years of injections. There are a number of well-known adverse events, however, a lesser-known and rarely reported adverse event of $\mathrm{rhGH}$ therapy is localized lipoatrophy. We report nine cases of localized lipoatrophy during $\mathrm{rhGH}$ therapy accounting for $14.5 \%$ of patients taking rhGH presenting to a single centre for routine follow-up over just a 2-month period. The development of localized lipoatrophy does not appear to be age, indication or dose-related but rather related to repeated administration of $\mathrm{rhGH}$ into a limited number of sites. The most likely putative mechanism is the local lipolytic action of growth hormone $(\mathrm{GH})$ itself, although the possibility of an excipient-based interaction cannot be excluded. Given the high prevalence of this adverse event and the potential to prevent it with adequate site rotation, we can recommend that patients be informed of the possible development of localized lipoatrophy. Doctors and nurses should closely examine injection sites at each visit, and site rotation should be emphasized during injection technique education.

\section{Learning points:}

- There are a number of well-known adverse events, however, a lesser-known and rarely reported adverse event of rhGH therapy is localized lipoatrophy.

- Examination of the injection sites at each visit by the treating healthcare practitioner.

- To advise the parents/caregivers/patients to change their injection site with each injection.

- To advise the parents/caregivers/patients to change the needles after every use.

- For parents, caregivers and patients to self-inspect their injection sites and have a high alert for the development of lipoatrophy and to then immediately report it to their doctor.

\section{Background}

Recombinant human growth hormone (rhGH) therapy became commercially available in 1985 for a variety of conditions (1). Prior to this, the supply of cadaveric growth hormone $(\mathrm{GH})$ was limited and restricted to children with proven GH deficiency (GHD) (2). The currently accepted evidence-based indications for the use of the rhGH have expanded the number of the rhGH recipients, and the recommended doses of rhGH vary by indication but range from $25-67 \mu \mathrm{g} / \mathrm{kg} /$ day administered subcutaneously (1). A number of well-known adverse events have been reported following its use; including, benign intracranial hypertension, slipped capital femoral epiphysis, and progression of scoliosis (3).

A less known and rarely reported side effect of daily rhGH therapy is localized lipoatrophy (3). On review of the currently available literature looking at lipoatrophy 
following rhGH administration, only one case report published in 1999 could be found. This particular publication reported a 9-year-old girl, with IGHD who developed severe localized lipoatrophy at injection sites after 6 years of rhGH therapy (4).

\section{Case presentation}

Ethical clearance was received from the Human Research Ethics Committee (Medical), Clearance Certificate number: M210316. After the presentation of the index case with lipoatrophy on rhGH therapy, we prospectively and thoroughly examined the injection sites of all patients attending the clinic who were on rhGH therapy. In the months of May and June 2020, there were a total of 62 patients seen who presented for routine follow-up visits and who were receiving rhGH therapy, and we are reporting on nine cases who were found to have developed lipoatrophy.

\section{Index case}

A 12-year-old male presented with concerns of poor growth. His height plotted between the 10th and 25th percentile, well below his mid-parental height (MPH) on the 75th centile. In view of the poor growth pattern, he underwent a clonidine GH stimulation test. The GH stimulation test revealed a peak GH value of $6.77 \mu \mathrm{g} / \mathrm{L}$. The rest of the laboratory values was within the normal range. The patient was commenced on rhGH at 10 years of age (Table 1).

After approximately 23 months of rhGH, the patient was noted to have developed a 'depression' in his right buttock at the injection site which had developed over a few weeks (Fig. 1). The dose of $\mathrm{rhGH}$ was $37 \mu \mathrm{g} / \mathrm{kg} / \mathrm{day}$ (Fig. 1 and Table 1).

Written informed consent for the publication of the below clinical image was obtained from the parents of the patient. The figure shows the development of lipoatrophy in our index case, in the right buttock area.

The subsequent Fig. 2, taken 3 months later showed resolution of lipoatrophy in the right buttock, and early development of lipoatrophy in the left buttock, his new preferred injection site.

\section{Cases 2-9}

Table 1 summarizes the details for the subsequent cases in our cohort as they had similar initial management, as well

Table 1 Table showing details of the nine patients who developed lipoatrophy.

\begin{tabular}{|c|c|c|c|c|c|c|c|c|c|}
\hline \multirow[b]{2}{*}{ Variable } & \multicolumn{9}{|c|}{ Cases } \\
\hline & 1 & 2 & 3 & 4 & $\underline{5}$ & 6 & 7 & 8 & $\underline{9}$ \\
\hline \multicolumn{10}{|l|}{ Demographic details } \\
\hline Gender & Male & Male & Female & Male & Male & Male & Male & Male & Male \\
\hline Age at first presentation* & 5y0m & $10 \mathrm{y} 9 \mathrm{~m}$ & $12 \mathrm{y} 6 \mathrm{~m}$ & $6 y 2 m$ & $6 y 7 m$ & $12 \mathrm{y0m}$ & 8y10m & $3 y 4 m$ & 11y0m \\
\hline \multicolumn{10}{|l|}{ Medical history } \\
\hline Perinatal course - normal & Yes & Yes & Yes & Yes & Yes & Yes & Yes & Yes & Yes \\
\hline Birth weight - normal & Yes & Yes & No & Yes & Yes & Yes & Yes & No & Yes \\
\hline Co-morbidities & No & No & No & Yes & No & Yes & No & No & No \\
\hline \multicolumn{10}{|l|}{ GH stimulation test with clonidine } \\
\hline Age at stimulation test* & $10 y 2 m$ & $10 y 10 m$ & 13y0m & $10 y 10 m$ & $8 y 4 m$ & $12 \mathrm{y} 5 \mathrm{~m}$ & $9 y 10 \mathrm{~m}$ & $3 y 5 m$ & $12 \mathrm{y} 10 \mathrm{~m}$ \\
\hline Peak GH level ( $\mu \mathrm{g} / \mathrm{L})$ & 6.77 & 10.80 & 11.00 & 16.00 & 3.57 & 1.93 & 3.60 & 8.50 & 8.20 \\
\hline Indication for rhGH & IGHD & GSS & SGA & ISS & IGHD & IGHD & IGHD & IGHD & IGHD \\
\hline \multicolumn{10}{|l|}{ Start of rhGH therapy } \\
\hline Age rhGH was started* & $10 y 2 m$ & $10 y 10 m$ & $13 y 11 \mathrm{~m}$ & 11y9m & 8y9m & $12 \mathrm{y} 4 \mathrm{~m}$ & $9 y 10 m$ & 3y8m & $12 \mathrm{y} 11 \mathrm{~m}$ \\
\hline Dose rhGH at start ( $\mu \mathrm{g} / \mathrm{kg} / \mathrm{day})$ & 36 & 37 & 44 & 43 & 39 & 44 & 20 & 44 & 36 \\
\hline \multicolumn{10}{|l|}{ Onset of localized lipoatrophy } \\
\hline Age at onset* & $12 \mathrm{y} 0 \mathrm{~m}$ & $12 \mathrm{y} 10 \mathrm{~m}$ & $14 y 2 m$ & $14 \mathrm{y} 11 \mathrm{~m}$ & $9 y 10 m$ & 13y0m & $11 \mathrm{y} 2 \mathrm{~m}$ & $6 y 8 m$ & $14 \mathrm{y} 1 \mathrm{~m}$ \\
\hline Dose of rhGH ( $\mu \mathrm{g} / \mathrm{kg} /$ day) & 37 & 34 & 40 & 34 & 37 & 40 & 26 & 43 & 30 \\
\hline Duration of rhGH (months) & 22 & 24 & 3 & 39 & 13 & 8 & 16 & 36 & 14 \\
\hline $\begin{array}{l}\text { Site(s) of localized lipoatrophy } \\
\text { development }\end{array}$ & Single & Single & Single & Single & Single & Multiple & Multiple & Multiple & Single \\
\hline $\begin{array}{l}\text { Localized lipoatrophy related to } \\
\text { the injection site }\end{array}$ & Yes & Yes & Yes & Yes & Yes & Yes & Yes & Yes & Yes \\
\hline
\end{tabular}

*Data presented as years (y), months (m).

GSS, genetic short stature; IGHD, isolated growth hormone deficiency; ISS, idiopathic short stature; rhGH, recombinant growth hormone; SGA, small for gestational age. 
as rhGH dosages both at the time of initiation of rhGH and at the onset of lipoatrophy.

Of the nine cases, eight were found to be male patients. Seven patients had a normal birth weight, one patient had a premature delivery, and one patient was small for gestational age (SGA). All of the patients otherwise had normal perinatal courses. Of the nine patients, only two had other comorbidities, one with asthma and the other with coeliac disease. Six of the patients were diagnosed with IGHD, and of the remaining three, one patient had genetic short stature, one patient was diagnosed with SGA, and one patient with idiopathic short stature. All patients in the case series had a single stimulation test, using clonidine. South African funders are satisfied with a single growth hormone stimulation test, accompanied by supportive auxological data.

The mean age at rhGH initiation was 10 years (range: 3-14 years old), and the mean dosage at which the rhGH was started was $39 \mu \mathrm{g} / \mathrm{kg} / \mathrm{day}$ (range: $20-44 \mu \mathrm{g} / \mathrm{kg} /$ day). The growth hormone product used by all patients in this case series was from a single manufacturer of a recombinant premixed growth hormone product. Each case was reported using the appropriate safety reporting channel, and batch and lot numbers were supplied. The Global Safety Department of the manufacturing company reported that there were no similar adverse events reported from other countries linked to the batch numbers in question, nor to any other batch numbers of the product. They re-iterated that localized lipoatrophy is a well-known adverse event.

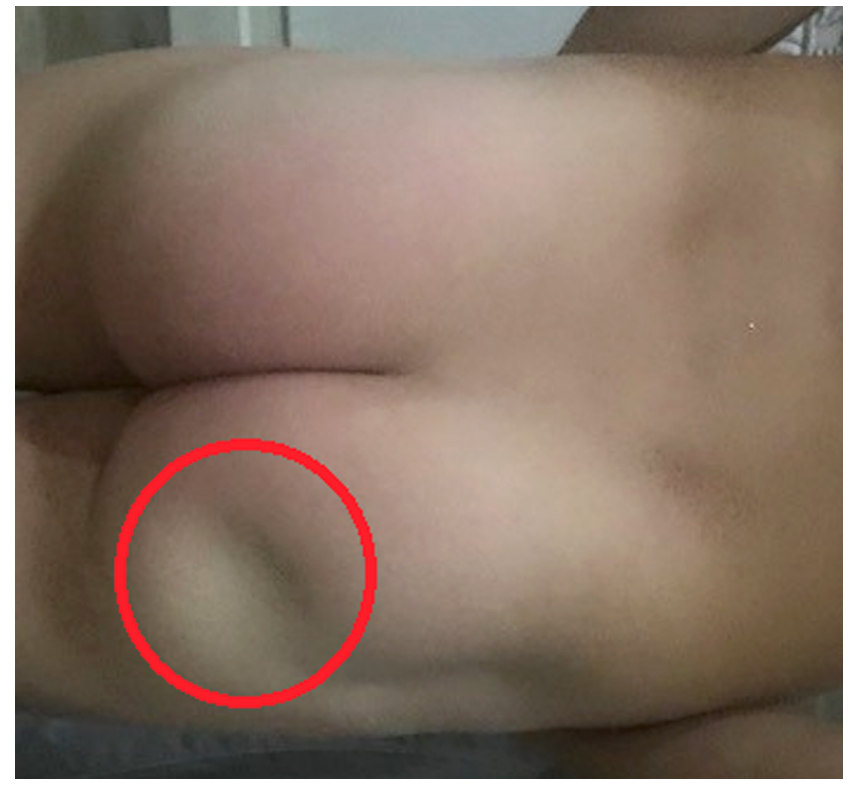

Figure 1

Lipoatrophy in a single site, on the right buttock in the index case.

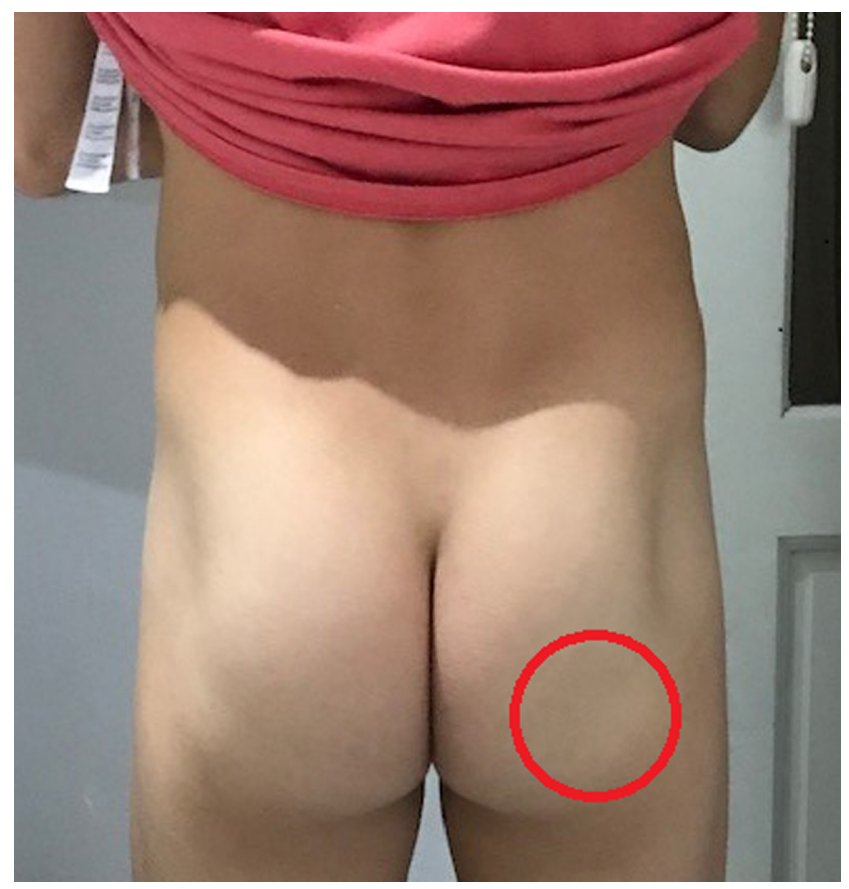

Figure 2

Lipoatrophy in a single site, on the left buttock in the index case.

Localized lipoatrophy was found in both single as well as multiple injection sites. Patients had been using rhGH for a mean duration of 19 months (range: 3-37 months), but this is not to imply that lipoatrophy only occurs after a long period of cumulative exposure. In fact, the index case had been injecting in the same site for 23 months but had only recently noticed the rapid development of lipoatrophy and queried if there had been any change in the formulation of the rhGH product. Following identification of the index case, all injection sites of patients on rhGH were thoroughly examined prospectively. Prior to this, the routine practice had been to enquire about the injection sites from the caregivers on history, with an occasional examination. The mean dose at the time of lipoatrophy onset was $36 \mu \mathrm{g} / \mathrm{kg} / \mathrm{day}$ (range: $26-43 \mu \mathrm{g} / \mathrm{kg} /$ day) and the children on average were 12 years old. In all cases, the patients were instructed on the injection technique by the same paediatric endocrinologist at the practice, and the injections were applied subcutaneously, with a pinched skin fold, using pens fitted with $4 \mathrm{~mm}$ Becton Dickinson (BD) microfine needles. Patients had been instructed to change the needles daily, and skin disinfection before s.c. injection is not routinely practiced. The patients had been uniformly educated on the appropriate storage of their rhGH which was a premixed solution. 


\section{Outcome and follow-up}

The development of lipoatrophy in our cohort did not appear to have a negative impact on growth velocity with only two out of the nine patients noted to have a decrease in growth velocity at the time of noticing the lipoatrophy during the consultation. In both cases, the small drop in growth velocity was of a magnitude that would have been expected during the normal course of growth hormone therapy. In the other seven patients, the growth velocities were not found to have decreased, despite the development of lipoatrophy.

Patients in our case series were advised to continue rhGH therapy, at the same dosages, but to rotate their injection sites at each injection. Only one patient in our case series elected to stop their rhGH therapy, whilst monitoring for resolution of the lipoatrophy. Personal communications with other endocrinologists who have seen similar cases suggest that the lipoatrophy resolves spontaneously over time by avoiding the injection area, which also occurred in our index case.

\section{Discussion}

Lipodystrophy is a disorder of adipose tissue, presenting either as lipohypertrophy or lipoatrophy (5). Lipoatrophy is defined as a large, often deep, retracted scar on the skin, as a result of damage to the s.c. fatty tissue (5). Some studies suggested an immunological aetiology, whereby biopsy samples obtained showed the presence of abundant mast cells and eosinophils in the specimen pointing towards a destructive inflammatory process (5).

Adults and children with untreated GHD have greater fat mass which has been shown to decrease with rhGH therapy (6). GH increases lipolysis via a direct effect of GH on adipocytes and indirectly via a decrease of lipoprotein lipase activity, reducing the flow of fatty acids to the adipocyte (7). GH also appears to have the potential to reduce both fat cell number and volume of mature adipocytes, thereby inhibiting the expansion of adipose tissue resulting in a reduction of total body fat (6).

Further evidence favouring a localized lipolytic effect of GH in the formation of lipoatrophy comes from a phase 3 study by Touraine et al. (7). The study was designed to assess the safety and efficacy of a long-acting GH formulation, obtained by the covalently binding polyethylene glycol (PEG) with rhGH (PEG-GH) (7). This formulation would allow for weekly s.c. injections, with similar efficacy to daily s.c. injections of rhGH (7). The long-acting GH formulation allowed for a progressive release of GH for up to 4 weeks
(7). The protocol required that PEG-GH be injected in the same thigh (in order to minimize variability), however, five cases of lipoatrophy were subsequently found, leading to the temporary suspension of the trial which was then reinitiated following the implementation of an injection site rotation plan (7). The subsequent occurrence of three new cases of lipoatrophy (including one case in a child) led to the termination of the study (7).

The study further demonstrated that the extensive areas of fat dissolution around the injection sites were due to $\mathrm{GH}$ being present subcutaneously long enough to have a localized lipolytic effect (7). The case of the 9-year-old girl investigated an immunological mechanism but could not find evidence of either a cross immune reaction with lipid tissue or directed immunity to the rhGH itself (4).

An alternative hypothesis is that one of the excipients involved in the production of the rhGH could be causing lipoatrophy. The production of biologicals is a complex process and excipients are used to improve stability and allow for effective delivery of the biomolecules (8). Examples of adverse events related to excipients include injection site reactions and anaphylaxis (8). All of our patients were on a single manufacturer's GH product.

Given what we know about the lipolytic effects of GH, it remains the most likely cause of the localized lipoatrophy in our cases. Half of the patients developed lipoatrophy at more than one injection site when more than one was used. We have not performed biopsies on any of our cases, nor have we chosen to investigate the possibility of anti-GH antibodies. The case report referring to the 9-yearold (4) stated a possible link between the development of lipoatrophy and the high dose ( $57 \mu \mathrm{g} / \mathrm{kg} / \mathrm{day})$ of the $\mathrm{rhGH}$ used. Lipoatrophy occurred in all of our patients within the recommended dose range. Various dosing ranges are used in particular conditions; for example, a dose of $25-50 \mu \mathrm{g} / \mathrm{kg} /$ day is used for the management of IGHD, compared to a dose of up to $67 \mu \mathrm{g} / \mathrm{kg} /$ day for ISS (9). The dosages for all the patients in our case series were within recommended ranges, with a mean dose of $36 \mu \mathrm{g} / \mathrm{kg} / \mathrm{day}$ (range: $26-43 \mu \mathrm{g} / \mathrm{kg} /$ day).

\section{Conclusion}

The development of lipoatrophy during rhGH therapy seems not to be a rare occurrence and may well be under detected and under reported in routine clinical practice. The exact mechanisms causing the localized lipoatrophy still need to be elucidated but a localized lipolytic effect of rhGH is favoured over a possible excipient-related effect, but further studies are needed. 


\section{Declaration of interest}

The authors declare that there is no conflict of interest that could be perceived as prejudicing the impartiality of the research reported.

\section{Funding}

This work did not receive any specific grant from any funding agency in the public, commercial, or not-for-profit sector.

\section{Patient consent}

Written consent has been obtained from the patient's parents for publication of the submitted article and accompanying images.

\section{Author contribution statement}

P D Chhiba is the primary author of this article and was involved in the literature review, article write up, and manuscript preparation. D Segal is the supervisor and co-author of this article and was involved in the literature review, and review and preparation of the manuscript. D Segal is the physician responsible for the patients included in the case series, who were followed-up at his practice.

\section{References}

1 American Academy of Paediatrics. Committee on drugs and committee on bioethics: considerations related to the use of recombinant growth hormone in children. Pediatrics 199799 122-129. (https://doi.org/10.1542/peds.99.1.122)

2 Segal D. Guideline for using growth hormone in paediatric patients in South Africa: treatment of growth hormone deficiency and other growth disorders. South Africian Medical Journal 200999 187-195

3 Cowell CT \& Dietsch S. Adverse events during growth hormone therapy. Journal of Pediatric Endocrinology and Metabolism 19958 243-252. (https://doi.org/10.1515/jpem.1995.8.4.243)

4 Buyukgebiz A, Aydin A, Dundar B \& Yorukoglu K. Localized lipoatrophy due to recombinant growth hormone therapy in a child with 6.7 kilobase gene deletion isolated growth hormone deficiency. Journal of Pediatric Endocrinology and Metabolism 199912 95-97. (https://doi.org/10.1515/jpem.1999.12.1.95)

5 Lopez X, Castells M, Ricker A, Velazquez EF, Mun E \& Goldfine AB. Human insulin analog-induced lipoatrophy. Diabetes Care 200831 442-444. (https://doi.org/10.2337/dc07-1739)

6 Chaves VE, Junior FM \& Bertolini GL. The metabolic effects of growth hormone in adipose tissue. Endocrine 201344 293-302. (available at: https://www.researchgate.net/publication/235690936). (https://doi. org/10.1007/s12020-013-9904-3)

7 Touraine P, D'Souza GA, Kourides I, Abs R, Barclay P, Xie R, Pico A, Torres-Vela E, Ekman B \& GH Lipoatrophy Study Group. Lipoatrophy in $\mathrm{GH}$ deficient patients treated with a long-acting pegylated $\mathrm{GH}$ European Journal of Endocrinology 2009161 533-540. (https://doi. org/10.1530/EJE-09-0422)

8 Ionova Y \& Wilson L. Biologic excipients: importance of clinical awareness of inactive ingredients. PLoS ONE 202015 e0235076. (https://doi.org/10.1371/journal.pone.0235076)

9 Wilson TA, Rose SR, Cohen P, Rogol AD, Backeljauw P, Brown R, Hardin DS, Kemp SF, Lawson M, Radovick S, et al. Update of guidelines for the use of growth hormone in children: the Lawson Wilkins pediatric endocrinology society drug and therapeutics committee. Journal of Pediatrics 2003143 415-421. (https://doi.org/10.1067/s00223476(03)00246-4)

Received in final form 3 August 202

Accepted 17 August 2021 